Diabetologia 9, 391-395 (1973)

(C) by Springer-Verlag 1973

\title{
Ventromedial Hypothalamic Lesions in Obese-Hyperglycaemic Mice (obob)
}

\author{
C. Chlouverakis, L. L. Bernardis, and D. Hojnicki \\ E.J. Meyer Memorial Hospital, Buffalo, N.Y., USA \\ Received: November 23, 1972, and in revised form: June 18, 1973
}

\begin{abstract}
Summary. Bilateral electrolytic lesions were placed in the ventromedial nucleus (VMN) of lean and obesehyperglycaemic mice (obob). The body weight of lean mice increased markedly and body composition studies revealed an increase in the percentage of body fat and a decrease of body water. Both serum insulin and glucose were increased. However, the body weight of obesehyperglycaemic mice (obob) with bilateral VMN lesions failed to increase, through their body fat showed a small increase and their body water decreased. These data
\end{abstract}

suggest that the VMN of obese-hyperglycaemic mice is functional. The small increase in the adiposity of $o b o b$ with bilateral VMN lesions might be due to the size of the lesion, which appeared to be smaller in the obob than in the lean mice.

Key words: Obese-hyperglycaemic mice, ventromedial nucleus, hypothalamus, obesity, serum insulin, glucose, body composition
Despite circumstantial evidence suggesting a hypothalamic involvement in the obese-hyperglycaemic syndrome in the mouse (obob) $[1-3]$ only two direct studies on the role of the hypothalamus have been reported in these animals. In one, bilateral electrolytic lesions of the ventrolateral hypothalamic nucleus (VLN) caused a decrease in food intake and body weight similar to that observed in normal animals with the same lesions, thus suggesting that the function of this nucleus is normal [4]. In the other study, goldthioglucose (GTG) was injected into obese-hyperglycaemic mice and was taken up in small quantities by the ventromedial nucleus (VMN) causing a small increase in body weight. It was suggested that the small uptake of gold-thioglucose by the VMN of $a b o b$ was due to an insulin-insensitivity of this nucleus [5].

On the basis of this latter study it could be inferred that the small increase in body weight (and presumably of food intake) of gold-thioglucose injected $o b o b$ was related to the small uptake of GTG and therefore to the small damage of the VMN. In the present study electrolytic lesions were produced bilaterally in the VMN of lean and $o b o b$ mice and their effect on body weight, carcass fat and water and also on serum glucose and insulin was examined.

\section{Materials and Methods}

Female obese-hyperglycaemic mice (obob) and their lean littermates $(O b O b$ and $O b o b)$ were obtained from the Jackson Laboratory (Bar Harbor, Maine) and shipped to the laboratory when 4 to 6 weeks old. After a period of two weeks they were anaesthetized with ether and inserted into a stereotaxic instrument (Baltimore Instrument Company). Holes were drilled into the skull with a dental drill and bilateral lesions were placed in the ventromedial hypothalamic area using a current of $1.0 \mathrm{~mA}$ which flowed for 5 sec from the bared tip of a $0.25 \mathrm{~mm}$ diameter spar varnish-coated stainless steel electrode. The coordinates used were: $2.8 \mathrm{~mm}$ anterior of the interaural line, $0.5 \mathrm{~mm}$ lateral of the mid-sagittal sinus and $5.7 \mathrm{~mm}$ ventral from the vertex. The tooth bar was raised to the same horizontal plane as the ear bars ${ }^{1}$. The incisions were closed with stainless steel clips and the animals returned to their cages. The "sham" operation involved the same procedure except that no current was applied.

Following the operation all animals were fed ad libitum and body weight was measured at weekly intervals. One hundred and twenty-five days after the operation, when the body weight had stabilized, the surviving animals were sacrificed by decapitation and blood was collected for serum glucose and insulin determination. The brains of all surviving animals and of those that had died before termination of the experiment were fixed in $10 \%$ buffered formalin for subsequent histologic analysis of the localization of lesions (Bernardis et al., 1963). Statistical analysis was performed on the data obtained only from animals in which lesions were placed accurately in both ventromedial nuclei. Serum glucose was determined on a Beckman Glucose Analyzer (Beckman Instruments, Inc., Fullerton, Calif.) and insulin by an adaptation [6] of the double immunoassay of Hales and Randle [7] using a commercially available kit (AmershamSearle Corp., Arlington Heights, Ill.) and a mouseinsulin standard. Body water and body fat were determined by previously published methods $[2,6]^{2}$.

1 The authors are grateful to Dr. D.G. Montemurro, University of Western Ontario, for his advice.

2 In the present study, the brain was used for histologic verification of the lesions and the remainder of the head discarded (and therefore not included in the determinations of body fat and body water). 


\section{Results}

Fifteen out of 20 lean VMN operated mice died during the first postoperative day. The cause of death is unknown and although asymmetrical or lateral lesions were found in some of the dead animals, in a large number of them the lesions were accurately placed. The remaining five mice of the lean group
In one the lesions were asymmetrical and in the other two the dorsomedial nucleus was also damaged.

The lesions of the VMN of the animals included in the final analysis were bilaterally symmetrical and did not impinge on the fornix, ventrolateral or dorsomedial nucleus. The lesions in the $o b o b$, however, appeared to be smaller despite the fact that they were produced under identical experimental conditions (Fig. 1).

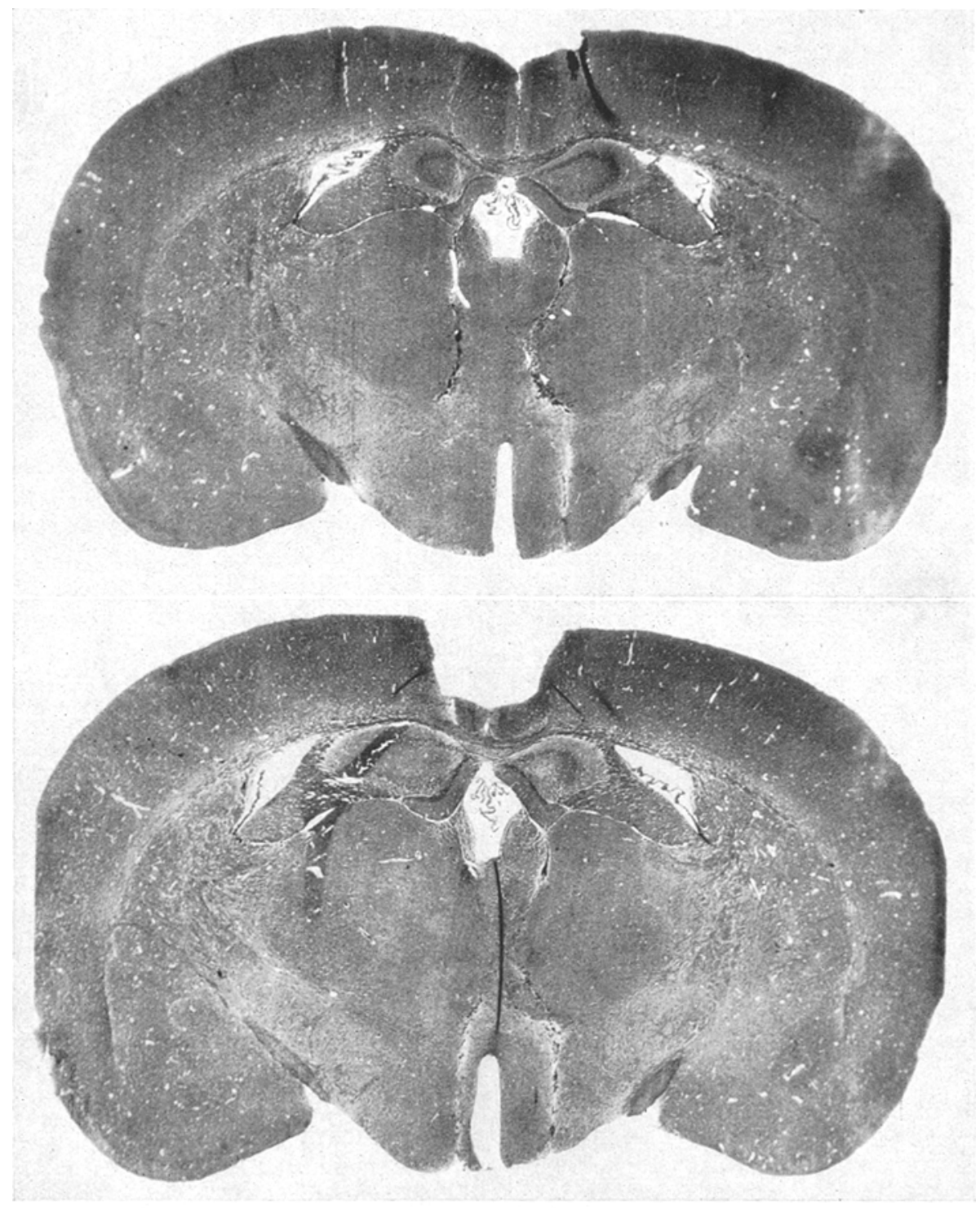

a

Nig. 1. Representative microphotographs of the hypothalamus of two obob (a) and two lean (b) mice with bilateral electrolytic lesions of the ventromedial nucleus (VMN). Photographs were taken at the coronal plane of the largest cross-section of the lesions (Cresyl Violet, $12.8 \times$ ). Note the smaller size of lesions in the $o b o b$ mice

survived the duration of the whole experiment. Four of the $22 \mathrm{obob}, \mathrm{VMN}$ operated, mice also died during the first post-operative day. Two more of this group and one of the $11 o b o b$ "sham" operated mice died later in the course of the experiment. Three of the obob VMN lesioned animals were excluded from the final analysis.
During the first ten post-operative days VMN lesioned obob mice failed to gain weight, but this effect of the operation was gradually overcome and at sacrifice, when the body weight of all animals had stabilized at a new level, VMN lesioned obob mice had a body weight equal to their "sham" operated controls. 
In contrast, the body weight of VMN lesioned lean mice increased steeply and at sacrifice it was significantly greater than that of the "sham" operated animals (Fig. 2).

Despite the similarity of body weight between the two groups of $o b o b$ mice the \% body fat was significantly greater $(p=0.025)$ and the $\%$ of body water significantly less $(p=0.02)$ in the VMN lesioned as significantly increased both these variables in lean mice (Table 1).

\section{Discussion}

The present study differs from that of Baile, Herrera, and Mayer (1970) who damaged the VMN of $o b o b$ and control mice by injecting these animals with

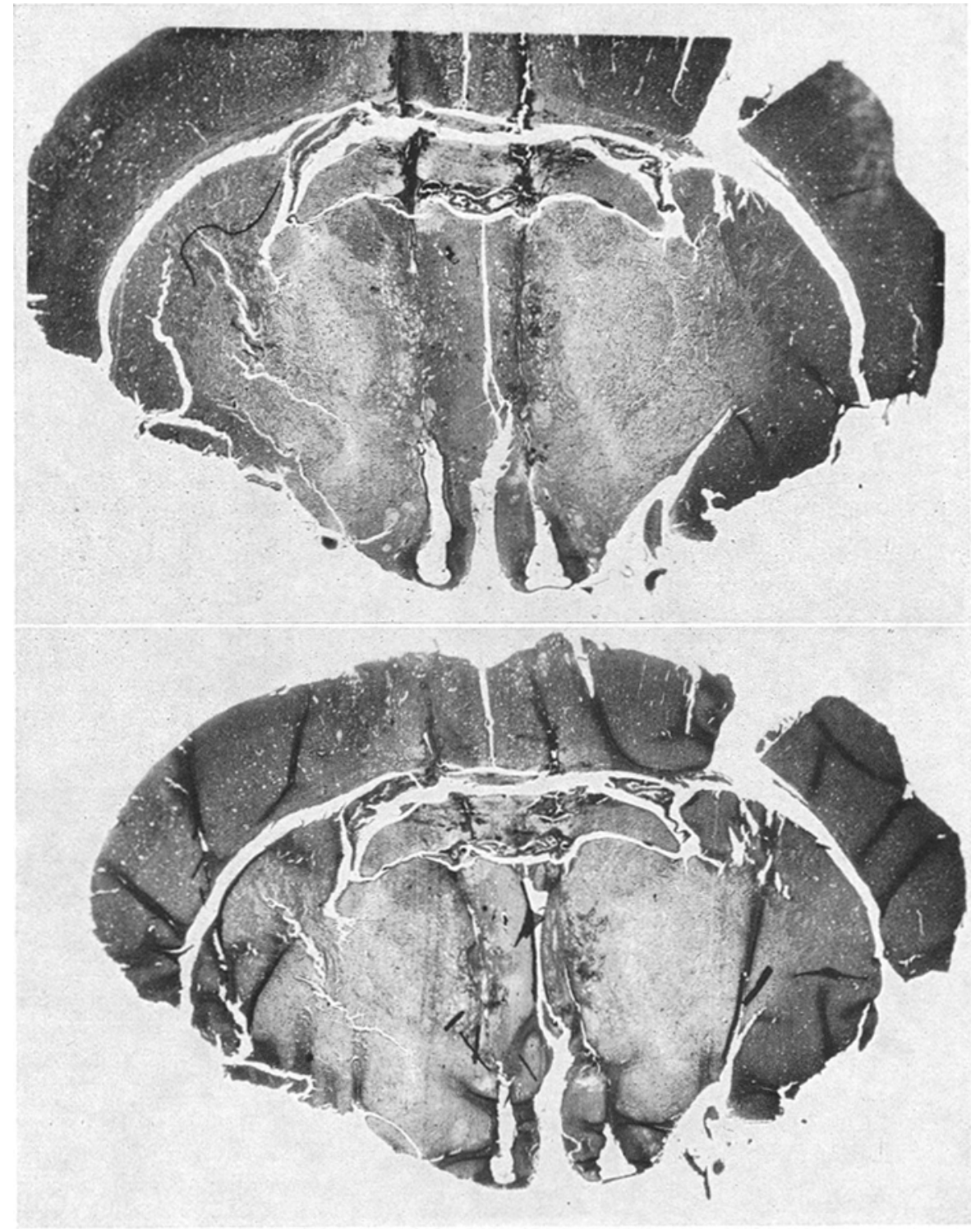

b

compared with the "sham" operated controls. Similarly, the $\%$ body fat was greater $(p<0.001)$ and that of body water less $(p<0.001)$ in the VMN lesioned than in the "sham" operated lean mice. There was no significant effect of VMN lesions on the serum glucose and insulin levels of $o b o b$ mice. However, such lesions gold-thioglucose (GTG). The latter, which was taken up only in small quantities by the VMN of $o b o b$ mice, caused a smaller damage to this nucleus and led to a mild increase in the body weight of $o b o b$ mice. In the present work we attempted to eliminate the difference in the size of lesions between $a b a b$ and lean mice by 
damaging the ventromedial nuclei electrolytically. It would appear, however, that this attempt was unsuccessful since the lesions of the obob seemed to be smaller in comparison with those in the VMN of lean mice ${ }^{3}$. Since the experimental conditions of lesioning have been identical in both groups of animals, this difference in the size of lesion, if present, is difficult to explain unless one postulates that the VMN of obob mice is more resistant to damage induced either by electrolysis or by the deposition of gold-thioglucose.

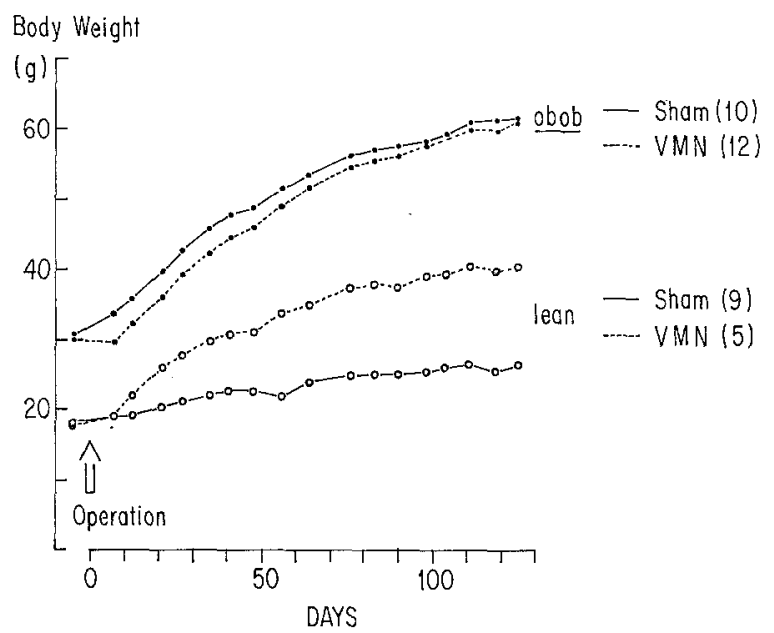

Fig. 2. Body weight of obese-hyperglycaemic mice (obob) and their lean littermates subjected to bilateral electrolytic lesions of VMN or to "sham" operation. Numbers in brackets indicate number of animals. accompanied by a decrease in their body water. The cause of this deficient response of $o b o b$ mice to the VMN damage cannot be evaluated on the basis of the present experiments. One possibility is that the ventromedial nucleus is functional in the $o b o b$ and that the magnitude of the response is proportional to the size of the VMN lesion [8]. Another possibility is that the capacity of the adipocytes to store fat is near its limit in the mature $o b o b$ mouse and expansion of the existing adipocytes beyond that limit cannot occur, despite the damage of a previously functional VMN. In this respect it is worth mentioning that although $o b o b$ mice are capable of expanding both the number and the size of their adipocytes as obesity develops, the obesity induced by VMN lesions is entirely due to adipose cell enlargement [9]. The view that the VMN of obob mice is functional is further supported by considering absolute rather than percentage changes of body fat. Thus, damage of VMN brought about an increase in body fat of $3.9 \mathrm{~g}$ in the $a b o b$ and $7.2 \mathrm{~g}$ in the lean mice.

The finding of a functional ventromedial nucleus in the $o b o b$ mice is in basic agreement with the conclusion of Coleman and Hummel, based on indirect evidence involving parabiosis of $o b o b$ with lean and $d b d b$ mice [10]. Furthermore, in conjunction with the previous study from this laboratory showing a functional ventrolateral nucleus of the $o b o b$ mice, the present results are compatible with the hypothesis proposed by one of the present authors suggesting that the homoeostatic mechanisms involved in the regulation of body fat in $o b o b$ mice are operative, but that

Table 1. \% body fat and body water, serum glucose and serum insulin (mean \pm S.E.M) of obob and lean mice lesioned in the ventromedial nucleus (VMN) and their "sham" operated control mice. Numbers in brackets indicate number of animals used

\begin{tabular}{llllr}
\hline & $\begin{array}{l}\% \\
\text { Body fat }\end{array}$ & $\begin{array}{l}\% \\
\text { Body water }\end{array}$ & $\begin{array}{l}\text { Serum glucose } \\
(\mathrm{mg} / \mathbf{1 0 0} \mathrm{ml})\end{array}$ & $\begin{array}{l}\text { Serum insulin } \\
(\mu \mathrm{U} / \mathrm{ml})\end{array}$ \\
\hline VMN obob (12) & $54.4 \pm 2.1$ & $25.6 \pm 0.9$ & $180.0 \pm 14.9$ & $823 \pm 216$ \\
"Sham obob(10) & $48.1 \pm \mathbf{1 . 9}$ & $28.3 \pm 0.7$ & $194.0 \pm \mathbf{1 5 . 6}$ & $1319 \pm \mathbf{3 4 5}$ \\
VMN lean (5) & $23.2 \pm 4.0$ & $\mathbf{4 4 . 4 \pm 4 . 1}$ & $167.4 \pm 5.4$ & $114 \pm 51$ \\
"Sham"lean (9) & $8.0 \pm 0.8$ & $59.6 \pm 1.2$ & $\mathbf{1 4 2 . 7 \pm 3 . 9}$ & $\mathbf{3 6 \pm 5}$ \\
\hline
\end{tabular}

Damage of the VMN brought about a marked increase in the body weight of lean mice and this increase was accompanied by an even more marked change in body composition, consisting of an increase of carcass fat and a decrease of carcass water. In addition, both serum insulin and glucose levels increased. In contrast to the changes of the lean mice, obese-hyperglycaemic mice, with their ventromedial nucleus damaged bilaterally, showed no increase in their body weight. There was, however, a small increase in their body fat,

3 The possibility of the existence of a difference in the size of lesions between $o b o b$ and lean mice was first entertained when reexamining the coronal sections of brain of lesioned mice during revision of this manuseript. At that time it was difficult to validate statistically such difference owing to distortions affecting the area adjacent to the lesions in some of the animals. this regulation is performed at a higher level of body fat $[1,2]$. In addition, the increased adiposity of the VMN lesioned $o b o b$ mice in the absence of a parallel increase of their circulating insulin is consistent with the view that excess adiposity in these animals can occur without significant hyperinsulinaemia [6].

Acknowledgement. This work was supported by Research Grant No. GR-32-MM-71 of the United Health Foundation of Western 'New York, by N.I.H. Grant No. 1 RO1 AM HD 16346-01 MET, and by a Buswell Fellowship. We are grateful to Mrs. Betty Stone for her excellent technical assistance.

\section{References}

1. Chlouverakis, C.: Induction of obesity in obesehyperglycemic mice (obob) on normal food intake. Fxperientia 26, 1262-1263 (1970) 
2. Chlouverakis, C.: Effect of caloric restriction on body weight loss and body fat utilization in the obesehyperglycemic mice (obob). Metabolism 21, 10-17 (1972)

3. Bray, G.A., York, D.: Genetically transmitted obesity in rodents. Physiol. Rev. 51, $598-646(1971)$

4. Chlouverakis, C., Bernardis, L.L.: Ventrolateral hypothalamic lesions in obese-hyperglycemic mice (obob). Diabetologia 8, 179-184 (1972)

5. Baile, C.A., Herrera, M. G., Mayer, J.: Ventromedial hypothalamus and hyperphagia in hyperglycemic obese mice. Amer. J. Physiol. 218, 857-863 (1970)

6. Chlouverakis, C., Dade, E.F., Batt, R.A.L.: Glucose tolerance and time sequenee of adiposity, hyperinsulinemia and hyperglycemia in obese-hyperglycemic mice (obob). Metabolism 19, 687-693 (1970)
7. Hales, N., Randle, P.J.: Immunoassay of insulin with insulin antibody precipitate. Biochem. J. 88, $137-145(1963)$

8. Liebelt, R.A., Ichinoe, S., Nicholson, N.: Regulatory influences of adipose tissue on food intake and body weight. Ann. N.Y. Acad. Sci. 131, 559-582 (1965)

9. Johnson, P.R., Hirsch, J.: Cellularity of adipose depots in six strains of genetically obese mice. $J$. Lipid Res. 13, 2-11 (1972)

10. Coleman, D.L., Hummel, K.P.: Comparison of the obesity syndromes of obese (ob/ob) and diabetic $(\mathrm{db} / \mathrm{db})$ mice. Diabetologia $8,49(1972)$

C. Chlouverakis, M.D.

E.J. Meyer Memorial Hospital

462 Grider Street

Buffalo, New York 14215

USA 